\title{
Análise da percepção da qualidade ambiental no destino turístico João Pessoa (PB)
}

\section{Analysis of perception of environmental quality in the tourist destination João Pessoa (PB, Brazil)}

\author{
Bruno Lima Machado
}

RESUMO: O presente artigo tem como principal objetivo analisar a percepção da qualidade ambiental do destino turístico João Pessoa (PB) a partir do olhar do turista. Como metodologia foi utilizado uma pesquisa empírica, de cunho quantitativo (survey), contendo a caracterização sociodemográfica dos turistas e a dimensão Ecotangiblidade da escala ECOSERV de Khan (2003). Foram entrevistados 390 turistas que visitaram o destino. Para o tratamento dos dados foram utilizadas as análises descritivas e fatorial. Os resultados obtidos revelaram que a cidade de João Pessoa (PB), no campo do turismo, de fato possui vocação natural para trabalhar seus atrativos inseridos no meio ambiente. Itens como temperatura, qualidade do ar, qualidade da água e aspectos que geram qualidade de vida para os moradores da cidade foram as variáveis que obtiveram as maiores médias. Em contrapartida, os itens sobre informativos acerca da preservação ambiental, acesso às lixeiras e coleta de lixo adequada foram as variáveis que obtiveram as menores médias. $\mathrm{E}$, de forma geral, os turistas avaliaram que a cidade possui uma qualidade ambiental satisfatória e acima da média total, de acordo com as sub-dimensões elencadas: "ambiental", "infraestrutura" e "visual" da dimensão Ecotangibilidade..

PALAVRAS-CHAVE: Percepção; Qualidade Ambiental; Destino Turístico; João Pessoa (PB); ECOSERV. 


\section{ABSTRACT}

The main objective of this article is to analyze the perception of the environmental quality of the tourist destination João Pessoa (PB) from the perspective of the tourist. As methodology, an empirical survey was used, with a sociodemographic characterization of the tourists and the dimension Ecotangiblity of the ECOSERV scale of Khan (2003). We interviewed 390 tourists who visited the destination. For the data treatment, the descriptive and factorial analyzes were used. The results showed that the city of João Pessoa (PB), in the field of tourism, has a natural vocation to work on its attractions in the environment. Items such as temperature, air quality, water quality and aspects that generate quality of life for city residents were the variables that obtained the highest averages. On the other hand, the items on information about environmental preservation, access to rubbish dumps and adequate garbage collection were the variables that obtained the lowest averages. And, in general, the tourists evaluated that the city has a satisfactory environmental quality and above the total average, according to the sub-dimensions listed: "environmental"; "infrastructure"; and "visual"; of the Ecotangibility dimension.

KEYWORDS: Perception; Environmental Quality; Tourist Destination; João Pessoa (PB); ECOSERV.

\section{Introdução}

As questões ambientais se constituem num dos temas considerados globais, havendo uma tomada de consciência universal de gravidade em torno delas, uma vez que a falta de soluções chega a ameaçar a própria existência humana. Nessa perspectiva, pode-se considerar um estado de crise socioambiental, crise esta, causadora de grandes impactos, cuja superação exige mudanças profundas não apenas nos padrões tecnológicos e científicos, como também de consumo por parte da sociedade (BORELLI, 2007).

A ação do homem sobre o meio ambiente tem provocado a perda da qualidade dos recursos naturais em muitos ecossistemas. A alteração, degradação, deterioração, impacto ou contaminação ambiental, gerados pela ação humana, possuem consequências negativas e, em muitos casos, elas podem ser irreversíveis (PIRES, 2010).

Beni (2002, p. 59-60) listou algumas formas de impactos negativos que são mais frequentes:

- A contaminação das águas pelos despejos domésticos e industriais;

- A contaminação da atmosfera ou do ar por gases de combustão dos automóveis e usinas geradoras de energia, esgotos a céu aberto, queima de lixo, desinfetantes e fungicidas;

-A contaminação do solo por pesticidas, despejos sólidos, detergentes e pela indústria da construção, águas de irrigação contaminada, desertificação, liberação de gases do subsolo na mineração e 
extração de petróleo e por derrames e vazamentos de petróleo, substâncias químicas e outros materiais de transportados a granel, no mar;

-A grave alteração causada pelas usinas de energia nuclear e muitas outras mais com as guerras recentes.

Tais exemplos são gerados pela má utilização do espaço físico que a natureza proporciona, além da falta de visão na aplicabilidade das ações mercadológicas em conformidade com o aspecto ecológico. Por outro lado, quando bem administrado e conservado, a natureza possui uma tendência a equilibrar seus componentes nas mais diversas situações, porém, as modificações causadas pela sociedade no ambiente físico-natural comprometem cada vez mais tal equilíbrio (MOTA, 1999).

O tema qualidade ambiental torna-se bastante complexo, bem como seus padrões e seus indicadores, pois neles estão contidos fatores subjetivos, que levam em conta a percepção que o indivíduo tem em relação ao seu ambiente e ao seu próprio modo de vida. Além disso, existem os fatores objetivos: econômicos, sociais, culturais e políticos, que se manifestam distintamente no espaço, possibilitando interpretá-lo de várias maneiras (GOMES; SOARES, 2004).

Foi a partir da década de 1980 que a definição da qualidade ambiental e, também, a qualidade de vida passaram por ter maior foco, fazendo destes conceitos chaves para o desenvolvimento social, econômico, técnicocientífico e pessoal (ARAÚJO, 2003). Este é um conceito em desenvolvimento e, por esse motivo, a falta de uniformidade pode ser considerada normal. Inicialmente, atribui-se um significado vagamente circunscrito e, posteriormente, à medida que vão sendo realizadas pesquisas e reflexões, o significado vai sendo esclarecido. Essa uniformidade não é necessária, pois qualidade ambiental consiste em um termo multidimensional e, por esse motivo, a sua mensuração se torna complicada.

Qualidade ambiental, conforme Johnson et al. (1997), é um conjunto de propriedades e características do ambiente, seja local ou geral, como eles incidem sobre os seres humanos e outros organismos. É uma medida da condição de um ambiente em relação com os requisitos de uma ou mais espécies e ou a qualquer necessidade humana ou propósito. Ou seja, é um termo geral que pode se referir a características variadas que se relacionam com o ambiente natural, bem como o ambiente urbano, como a purificação do ar e água ou sua poluição, o ruído e os efeitos potenciais que tais características podem ter sobre a saúde física e mental causada pelas atividades humanas nas cidades, etc. Nucci (2008) lista uma sequência de indicadores que apontam para a percepção da qualidade ambiental, são eles: clima, poluição atmosférica, poluição da água, poluição sonora, poluição visual, resíduos, enchentes, cobertura vegetal, áreas verdes e espaços livres de construção, verticalização e densidade populacional.

Já o Glossary of Environment Statistics ${ }^{1}$ (1997) cita que a qualidade ambiental é o estado das condições do meio ambiente, expressas em 
termos de indicadores ou índices relacionados com os padrões de qualidade ambiental. E o European Environment Information and Observation Network $(\text { EIONET) })^{2}$ acrescenta que esse termo pode se referir a características variadas, tais como pureza ou poluição da água e do ar, ruído, acesso aos espaços abertos, os efeitos visuais das áreas construídas, e os efeitos potenciais que tais características podem ter na saúde física e mental dos indivíduos.

Para Fulgêncio (2007, p 523), qualidade ambiental

é um termo empregado para caracterizar as condições do ambiente segundo um conjunto de normas e padrões ambientais pré-estabelecidos. A qualidade ambiental é utilizada como valor referencial para o processo de controle ambiental. $O$ resultado dos processos dinâmicos e interativos dos elementos do sistema ambiental define-se como o estado do meio ambiente, numa determinada área ou região, conforme é percebido objetivamente, em função da medição da qualidade de alguns de seus componentes, ou mesmo subjetivamente, em relação a determinados atributos, como a beleza, o conforto, o bem-estar.

Bitar (2004, p. 62) conceitua qualidade ambiental como uma

\begin{abstract}
expressão geralmente, parametrizada apenas pela verificação prática do caráter de conformidade das condições desse meio ambiente em relação a exigências ambientais (normas e requisitos legais) previamente estabelecidas, sejam de âmbito local, regional, nacional, sejam de âmbito internacional.
\end{abstract}

De acordo com Mattos (2005), a qualidade ambiental é entendida como as condições apresentadas em um dado momento pelos dois subsistemas (físico-natural e socioeconômico) e suas interações (englobando, portanto, o conceito de qualidade de vida) e cuja avaliação pode ser feita por meio de indicadores. Ou seja, a definição está relacionada a uma série de conceitos que refletem as ações das pessoas nos diversos ambientes por elas usados, bem como as percepções elaboradas sobre tais ambientes.

Para Boersema (2009) a qualidade do meio ambiente pode ser avaliada por meio da comparação do estado atual com o esperado e com o padrão, isto é, observando-se que o atual estado do meio ambiente ou de suas partes pode mudar devido à intervenção humana ou à flutuação natural, e a ênfase aqui será sobre as mudanças induzidas ou intensificadas pelo homem. Se as pessoas, em uma dada sociedade, percebem as diferenças ou presumem mudanças como efeitos negativos, então, elas estão se referindo a problemas ambientais. Em um alto nível, os problemas 
ambientais podem ser considerados como a deterioração das relações entre a sociedade e o meio ambiente, cujo relacionamento é julgado como insustentável.

E é a partir dessa definição de Boersema (2009) que se pode passar a ver a questão da percepção dessa qualidade ambiental, que está intrinsecamente ligada à qualidade de vida, por parte daqueles que vivenciam e interagem com o meio ambiente visitado, ou seja, o destino turístico em si. Vem sendo bastante abordado esse aspecto no meio ambiente: a correta percepção que os sujeitos realçam sobre o tema, principalmente com relação a real perspectiva das variáveis ambientais e seus efeitos sobre o ambiente como um todo.

Fernandes et al. (2009, p. 01) definem percepção ambiental "como sendo uma tomada de consciência do ambiente pelo homem, ou seja, o ato de perceber o ambiente que se está inserido, aprendendo a proteger e a cuidar do mesmo". Quer dizer, cada pessoa nota, reage e reage de formas não programadas às ações acerca do ambiente no qual vive ou se depara. Os autores continuam afirmando que "as respostas ou manifestações daí decorrentes são resultado das percepções (individuais e coletivas), dos processos cognitivos, julgamentos e expectativas de cada pessoa".

Já Pacheco e Silva (2007, p. 02) dizem que o conceito de

percepção ambiental é definido como a operação que expõe a lógica da linguagem que organiza os signos expressivos dos usos e hábitos de um lugar. É uma explicitação da imagem de um lugar, veiculada nos signos que uma comunidade constrói em torno de si. Nesta acepção, a percepção ambiental é revelada mediante uma leitura semiótica da produção discursiva, artística, arquitetônica, etc. de uma comunidade.

Sendo assim, discutir esse conceito não é, entretanto, uma situação de dizer quais das representações podem ser correspondidas para caracterizar melhor uma realidade apresentada, mas a discussão deve elucidar as perspectivas científicas, sociais ou políticas veiculadas através da utilização desse conceito. Devem-se estabelecer conexões entre os segmentos que aborda o meio físico e a reflexão sobre as relações desse meio com a subjetividade, ou seja, pontos da psicologia cognitiva.

Fernandes et. al. (2009) voltam a afirmar que o estudo dessa percepção tem fundamental importância para a melhor compreensão das inter-relações existentes entre o ser humano e o ambiente, além do entendimento das expectativas, anseios, satisfações e insatisfações, julgamentos e condutas.

Algo que dificulta esse entendimento são as variadas influências que o indivíduo sofre ao decorrer da sua vida e, também, a percepção diferente dos valores estabelecidos por várias culturas e grupos socioeconômicos, 
que os quais desempenham funções distintas a partir do plano social até chegar ao ambiente. Bassani (2001, p. 52) observa que a

percepção ambiental é entendida como a experiência sensorial direta do ambiente em um dado momento, não sendo considerada um processo passivo de mera recepção de informações, uma vez que implica certa estruturação e interpretação da estimulação ambiental pelas pessoas. [...] ao perceber um dado ambiente, a pessoa já interpreta os estímulos desse ambiente e, nessa interpretação, estão envolvidas aprendizagens que pode ter tido durante sua vida e suas experiências com tal ambiente.

O que Bassani (2001) quis enfatizar é que a percepção está agregada a uma série de conceitos que contêm diversos tipos de comportamentos dos indivíduos, sejam eles de afeição, perceptivos e cognitivos, que foram contraídos ao longo das suas vidas e das relações com os diversos outros ambientes aos quais têm sido expostos. Isto é, a definição sempre estará sujeita a indicadores como o bem-estar, aspirações, preferências, satisfação, felicidade, percepção ambiental e cognição ambiental, dentre outros.

Voltando essas definições ao caso estudado na presente pesquisa, a percepção do turista pode trazer contribuição para a compreensão desses aspectos no âmbito do turismo na destinação. Beni (2002, p. 246) assegura que a "percepção é o processo pelo qual o indivíduo seleciona, organiza e interpreta a informação para criar quadros do mundo; é uma apreensão da realidade através dos sentidos".

Então, levando em consideração os conceitos e reflexões sobre qualidade ambiental, sua percepção e a crescente preocupação com as ações do homem em relação ao meio ambiente, é imperativo trazer tais aspectos para a realidade do turismo, onde a interação entre sociedade e natureza também acontece de forma conflituosa em diversos casos. Segundo, Anjos, Anjos e Rados (2010, p. 127)

a busca pela sustentabilidade e a participação da comunidade local se apresentam como novos desafios para o desenvolvimento de propostas para o planejamento do turismo. Tal desafio está ligado ao princípio de que o desenvolvimento turístico deve se basear no equilíbrio entre a conservação ambiental e cultural, a viabilidade econômica e a justiça social.

Em consequência do equilíbrio entre tais aspectos, otimiza-se 0 potencial de contribuir para o bem-estar do ser humano e para o meio ambiente, minimizando os impactos ambientais e sociais (HALL, 2001). A OMT, conforme Anjos, Anjos e Rados (2010) afirma, considera como sustentável e seguro o turismo que possui entorno humano e institucional 
envolvendo aspectos físicos e ambientais capazes de influenciar diretamente as condições de saúde, a qualidade de vida e a segurança das pessoas e comunidades. Isto significa observar, de forma ímpar, a relação entre os seres humanos, suas atividades e o uso que fazem do espaço que os envolve, ou seja, mais especificamente, os destinos turísticos.

Sachs (2000) lista seis dimensões importantes, que devem ser observadas quando se fala em sustentabilidade em destinos turísticos: 1) Ecológica: capacidade de carga do ecossistema para o uso turístico; 2) Social: equidade na distribuição dos benefícios trazidos pelo turismo; 3) Cultural: respeito às diferenças, valorização das minorias e integração cultural; 4) Política: participação da comunidade local e dos visitantes nas decisões; 5) Econômica: desenvolvimento econômico dos destinos turísticos; e 6) Espacial: uso adequado dos territórios turísticos. Com isso, quando se fala em percepção da qualidade ambiental em destinos turísticos, além dos aspectos individuais dos turistas, leva-se em consideração, também, os aspectos inerentes ao planejamento que vem sendo aplicado pelo poder público em conformidade com a realidade ambiental, social, cultural e econômica do destino. Elevando, portanto, a importância de tudo o que é apresentado no destino, desde dos aspectos mais comuns aos serviços turísticos, até aqueles que são percebidos no entorno, no clima, na paisagem, na conservação, etc.

Sendo assim, levando em consideração os conceitos visitados até o momento, o objetivo deste artigo é analisar a percepção da qualidade ambiental do destino turístico João Pessoa (PB) a partir do olhar do turista. Como isso, poder-se-á entender como o destino em questão, através da opinião dos turistas, consegue transparecer sua gestão e planejamento por meio do que é apresentado e percebido pelo turista que visita a cidade.

\section{Metodologia}

Como procedimento metodológico foi feita uma pesquisa empírica na cidade de João Pessoa (PB), de cunho quantitativo (survey), contendo a caracterização sociodemográfica do turista e utilizando a dimensão Ecotangibilidade, da escala ECOSERV de Khan (2003), que compreende a percepção da qualidade ambiental do destino visitado. Usou-se a Escala de Likert de cinco pontos, com uma sexta opção "sem opinião". Cada afirmativa do instrumento de pesquisa variava de "discordo totalmente", "discordo parcialmente", "não discordo, nem concordo", "concordo parcialmente", "concordo plenamente".

Ressalta-se que a pontuação máxima das médias obtidas na pesquisa chega a 5 pontos e a pontuação mínima chega a 1 ponto. Isto é, a pontuação de cada variável, que compõe a dimensão Ecotangibilidade, pode oscilar entre 1 e 5, sendo que 1 a pontuação mais baixa e 5 a mais alta. Então, a percepção da qualidade ambiental, com variação dos itens observados, pode ser baixa, quando a média estiver mais perto de 1 ou a percepção da qualidade ambiental pode ser alta, quando a pontuação estiver perto de 5 . 
A escala ECOSERV é uma versão adaptada das escalas SERVQUAL de Parasuraman, Zeithami e Berry (1985) e SERVPERF de Corin e Taylor (1992) que foi desenvolvida por Khan (2003) com o objetivo de investigar e avaliar a qualidade ambiental e dos serviços turísticos para a satisfação do cliente no mercado de ecoturismo. De acordo com o estudo proposto por Khan (2003) a ECOSERV tem 30 itens e aborda seis dimensões, ou seja, cinco dimensões advindas da escala tradicional SERVQUAL, mais uma sexta dimensão, a Ecotangibilidade.

A dimensão Ecotangibilidade refere-se à análise e avaliação das instalações do entorno do destino e dos aspectos ambientais de forma geral, com o intuito de medir os impactos ambientais e culturais de um destino com ênfase nos recursos naturais (KAHN, 2003). Sendo assim, verifica-se se existem equipamentos que minimizem a degradação ambiental, se há instalações seguras em termos ambientais e se os aspectos gerais do meio ambiente do destino (ar, água, temperatura, etc.) estão condizentes com o que deveria ser esperado de acordo com a localização geográfica do destino.

Dos 22 itens mencionados no SERVQUAL, 19 foram usados na ECOSERV, três dos itens foram adaptados e 8 itens foram adicionados, resultando num total de 30 itens para medir as expectativas dos ecoturistas ${ }^{3}$ sobre qualidade ambiental e de serviço turístico. Portanto, as seis dimensões do ECOSERV são: Ecotangibilidade, Segurança (ou Garantia), Confiabilidade, Responsividade, Empatia e Tangibilidade. No caso do destino turístico João Pessoa(PB), a escala ECOSERV, na dimensão Ecotangibilidade, foi adaptada para que a compreensão do turista acontecesse de forma mais fácil. Com isso, segue a seguir as variáveis utilizadas, que no total foram 13:

ECO1: No geral, o aspecto visual de João Pessoa está em bom estado de conservação.

ECO2: As lixeiras de coleta seletiva estão em locais adequados e de fácil acesso.

ECO3: Os aspectos arquitetônicos da infraestrutura de João Pessoa, acesso, sinalização, estacionamento, etc. estão integrados à paisagem local.

ECO4: A infraestrutura dos atrativos turísticos de João Pessoa é adequada ao meio ambiente.

ECO5: A preservação do meio ambiente de João Pessoa está em bom estado.

ECO6: O material informativo sobre a preservação ambiental em João Pessoa está facilmente disponível.

ECO7: As praias de João Pessoa estavam sempre limpas.

ECO8: A coleta de lixo funciona de forma adequada mantendo as ruas sempre limpas.

ECO9: João Pessoa apresenta boa qualidade do ar. 
ECO10: João Pessoa apresenta boa qualidade da água.

ECO11: A temperatura de João Pessoa é adequada.

ECO12: Os moradores de João Pessoa têm comportamento ambiental.

ECO13: A cidade de João Pessoa tem aspectos que geram boa qualidade de vida para os moradores.

A amostra da pesquisa se deu pelo cálculo amostral do universo pesquisado, obtendo o número de 390 entrevistados, com nível de confiança em $95,5 \%$ e estimativa de erro em $5 \%$ (GIL, 1999). A coleta de dados se deu no Aeroporto Internacional Castro Pinto, localizado na grande João Pessoa, ouvindo apenas turistas que estavam de retorno para suas casas, no intuito de ouvir exatamente as percepções da viagem que acabara de acontecer neste destino, ou seja, coletar as lembranças das experiências e vivências bem recentes sobre a qualidade ambiental do destino.

Para a análise dos dados obtidos, foram utilizadas técnicas quantitativas, como a descritiva (percentual, média, desvio padrão, assimetria, curtose) e a análise fatorial. A média é a soma de todos os valores observados divididos pelo número total de observações; o desvio padrão mede a dispersão dos valores individuais em torno da média, inferindo sobre variância de resposta da variável no conjunto de dados; a assimetria indica o grau de distorção da distribuição em relação a uma distribuição simétrica, que podem ser assimétrica positiva, assimétrica negativa e simétrica; e a curtose indica a forma da curva de distribuição em relação ao seu achatamento, podendo ser leptocúrtica, mesocúrtica e platicúrtica (CORRAR; PAULO; DIAS, 2012). Morôco (2010) considera que é recorrente a aplicação da assimetria e curtose para analisar a aceitação da apropriação da distribuição normal das variáveis. Já para o processamento de dados foi utilizado o SPSS versão 19.0.

\section{Caracterização da área em estudo}

João Pessoa é a capital do estado da Paraíba, que se localiza na parte leste da região nordeste do Brasil (Figura 1). Atualmente possui um pouco mais de 800 mil habitantes (IBGE, 2018) e tem cerca de $211 \mathrm{~km}^{2}$ de extensão de área. No ano de 2019, a capital paraibana completará 434 anos, sendo, portanto, o $3^{\circ}$ centro urbano mais antigo do Brasil, segundo a Empresa Paraibana de Turismo (PBTUR). 


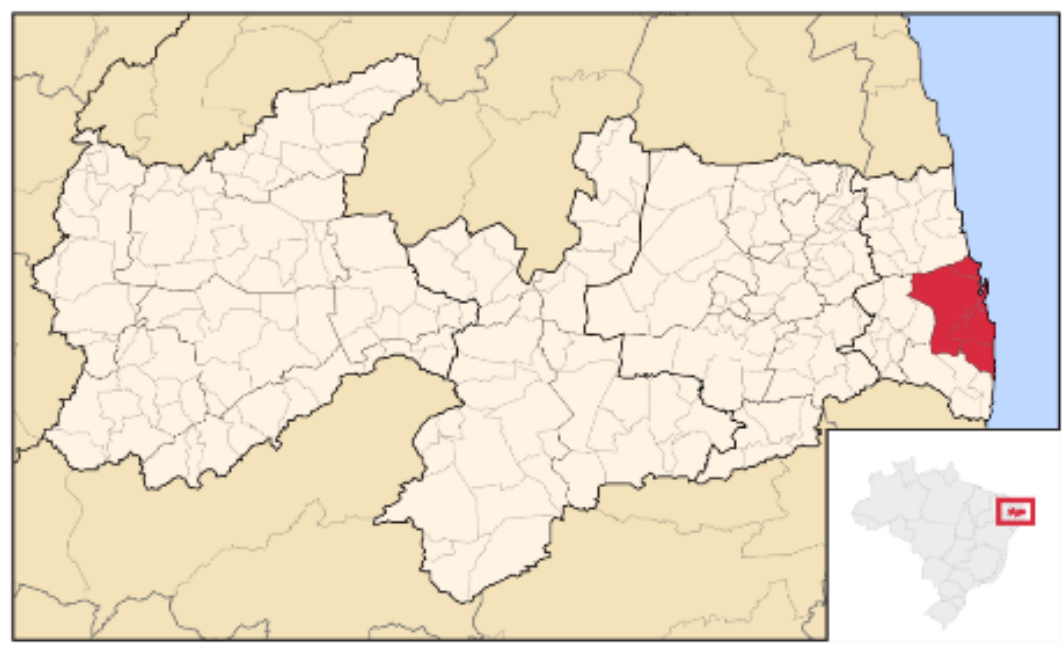

Figura 1 - Localização geográfica da cidade de João Pessoa (PB) Figure 1 - Geographical location of the city of João Pessoa (PB)

Fonte: Raphael Lorenzeto de Abreu (2006)

Source: Raphael Lorenzeto de Abreu (2006)

A escolha da cidade de João Pessoa (PB) se deu por sua importância em termos de atrativos turísticos que, por si só, demonstram vocação natural e que estão inseridas no âmbito variado de meio ambiente. Alguns dos principais atrativos da cidade estão listados em seguida:

-As praias urbanas de Tambaú, Cabo Branco (as mais conhecidas - Figura 2), Manaíra e Bessa que estão continuamente próprias para banho;

-As Piscinas Naturais de Picãozinho (Figura 3) e Seixas que são formações de corais perto da costa que recebem visitas regulares de turistas e banhistas;

-O Jardim Botânico de João Pessoa, conhecido popularmente por Mata do Buraquinho, que fica localizado no centro da cidade com 515 hectares de área e é considerada a maior reserva de Mata Atlântica na cidade;

- As falésias do Cabo Branco, onde estão localizados o Farol e a Estação de ciências, cultura e arte;

- O Centro Histórico da cidade, que beira os dois principais rios do Estado (Rio Sanhauá e Rio Paraíba), onde se deu o início e a expansão da população, local com rica presença de mangues e ilhas fluviais (Figura 4).

-O Parque Zoobotânico Arruda Câmara, também localizado no centro da cidade, local de preservação da fauna e flora e com objetivo de educação ambiental para a população;

- O Pôr-do-sol na Praia do Jacaré, localizado no município vizinho de Cabedelo, pertencente à região metropolitana, mais conhecido pela execução diária do Bolero de Ravel; e 
-Areia Vermelha, também no município de Cabedelo, banco de areia que surge quando a maré está baixa, localiza-se cerca de $1,5 \mathrm{~km}$ da costa.

-Também fazem parte dos principais atrativos naturais de João Pessoa, incluídas em diversos pacotes de passeios locais, são as praias do Litoral Sul e Norte do estado.

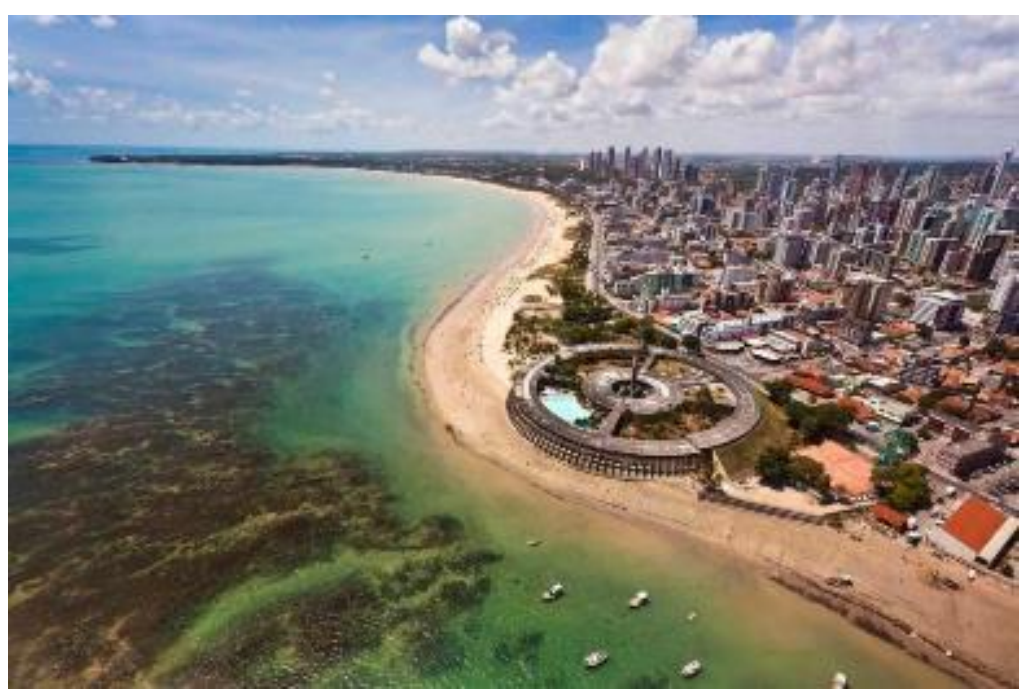

Figura 2: Parte do litoral urbano da cidade de João Pessoa visto de cima.

Figure 2: Part of the urban coastline of the city of João Pessoa seen from above.

Fonte: Alessandro Potter (2014).

Source: Alessandro Potter (2014).

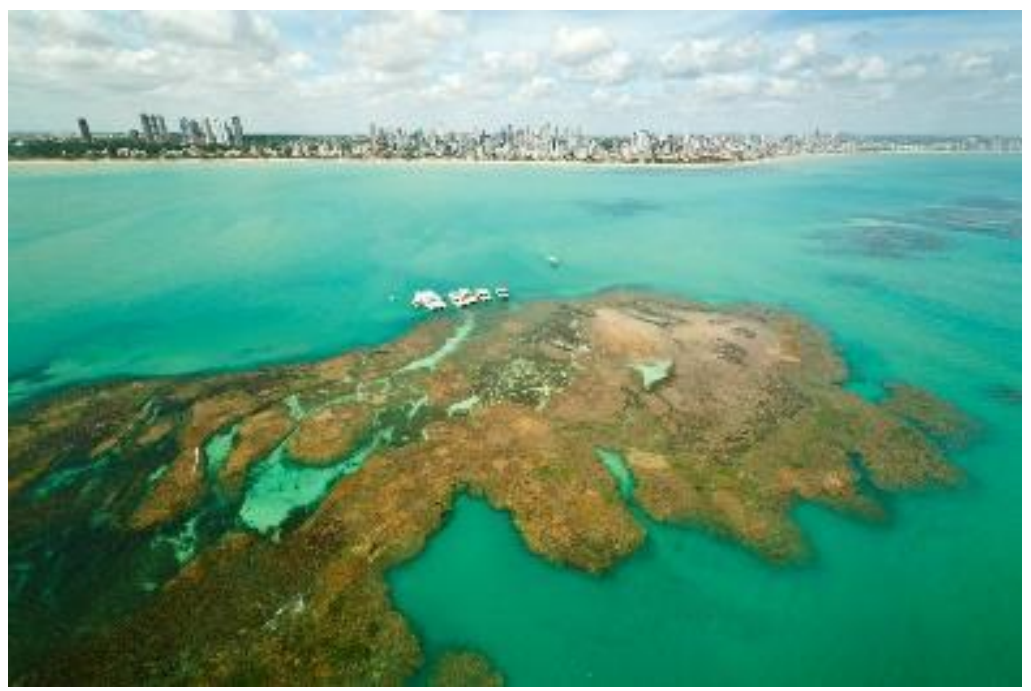

Figura 3: Piscinas Naturais de Picãzinho.

Figure 3: Natural Pools of Picazinho.

Fonte: Alessandro Potter (2014).

Source: Alessandro Potter (2014). 


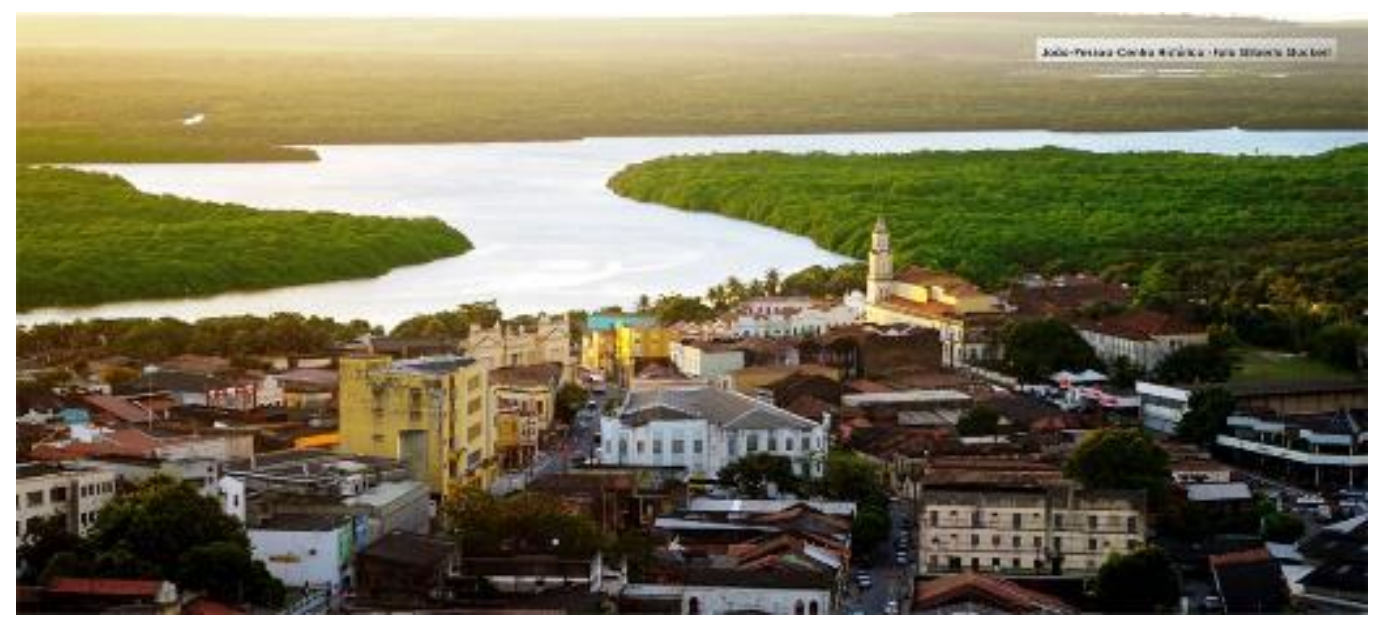

Figura 4: Centro Histórico de João Pessoa com vista para o Rio Sanhauá.

Figure 4: Historic Center of João Pessoa overlooking the Sanhauá River.

Fonte: José Marques (2012).

Source: José Marques (2012).

\section{Resultados e discussões}

Sobre as características dos entrevistados, o número de turistas que foram abordados na pesquisa, conforme cálculo da amostra, foi satisfatório para entender a análise proposta acarretando a apresentação de dados pertinentes sobre o perfil destes. Sendo assim, pode-se concluir que a maioria dos turistas são mulheres (56\%); os visitantes possuem uma faixa etária predominante entre 21 e 50 anos (60\%); do total de visitantes, a maioria encontra-se casados (51\%); eles possuem formação superior ou encontram-se em formação (58\%); eles dispõem de uma renda mensal entre um a oito salários mínimos (55\%) e outra fatia importante dispõe de oito ou mais de quatorze salários mínimos (33\%); eles provêm principalmente da região sudeste (48\%); eles visitam a cidade no intuito de lazer/recreação ou férias (68\%); a maioria visita a cidade por conta própria (68\%); e a maioria estava na cidade pela primeira vez (56\%).

Já em relação à percepção da qualidade ambiental do destino, de acordo com a Tabela 1, pode-se observar que a média individual entre as treze variáveis da dimensão Ecotangibilidade oscilou de 3,24 do item ECO6 e 4,48 do item ECO11, obtendo uma média geral ponderada de 4,02. No caso específico dos turistas ouvidos na pesquisa, observa-se que nenhuma variável, das 13, obtiveram média ponderada abaixo de 3 e em muitos variáveis a pontuação ficou entre 4 e 5, significando que a percepção da qualidade ambiental é considerada alta, quer dizer, João Pessoa possui uma alta qualidade ambiental de acordo com as variáveis contidas na dimensão Ecotangibilidade. 
Tabela 1: Análise descritiva da dimensão Ecotangibilidade.

Table 1: Descriptive analysis of the Ecotangibility dimension.

\begin{tabular}{c|r|r|r|r|r}
\hline $\begin{array}{c}\text { Dimensões } \\
\text { e Variáveis }\end{array}$ & Válidos & Média & $\begin{array}{c}\text { Desvio } \\
\text { Padrão }\end{array}$ & Assimetria & Curtose \\
\hline ECO1 & 390 & 4,17 & 0,87843 & $-1,475$ & 2,723 \\
\hline ECO2 & 371 & 3,72 & 1,06705 & $-0,825$ & 0,197 \\
\hline ECO3 & 387 & 3,91 & 1,02134 & $-0,927$ & 0,410 \\
\hline ECO4 & 387 & 3,94 & 1,03487 & $-0,928$ & 0,286 \\
\hline ECO5 & 387 & 4,02 & 0,98548 & $-0,967$ & 0,469 \\
\hline ECO6 & 365 & 3,24 & 1,51887 & $-0,338$ & $-1,376$ \\
\hline ECO7 & 383 & 4,06 & 0,96875 & $-1,046$ & 0,811 \\
\hline ECO8 & 369 & 3,83 & 1,19202 & $-0,871$ & $-0,227$ \\
\hline ECO9 & 388 & 4,43 & 0,82790 & $-1,666$ & 2,923 \\
\hline ECO10 & 382 & 4,37 & 0,87126 & $-1,517$ & 2,252 \\
\hline ECO11 & 389 & 4,48 & 0,85708 & $-1,825$ & 3,117 \\
\hline ECO12 & 367 & 3,91 & 1,14382 & $-0,864$ & $-0,171$ \\
\hline ECO13 & 379 & 4,23 & 0,96091 & $-1,319$ & 1,294 \\
\hline $\begin{array}{l}\text { Média Geral Ponderada } \\
\text { Ecotangibilidade }\end{array}$ & 4,02 & & & \\
\hline
\end{tabular}

Fonte: Resultados da pesquisa (2014)

Source: Search results (2014)

As variáveis que tiveram maior média foram a $\operatorname{ECO11}(4,48)$, seguida da ECO9 $(4,43)$, ECO10 $(4,37)$ e ECO13 $(4,23)$. Todas elas tratam de assuntos referentes diretos da natureza, porém que podem sofrer com a interferência do homem:

-ECO11: A temperatura de João Pessoa é adequada.

-ECO9: João Pessoa apresenta boa qualidade do ar.

-ECO10: João Pessoa apresenta boa qualidade da água.

-ECO13: A cidade de João Pessoa tem aspectos que geram boa qualidade de vida para os moradores.

Os números levam a crer que o destino turístico João Pessoa possui de fato uma vocação que inspira a conservação da natureza que está essencialmente presente na cidade, o que é confirmado por Mota (1999), em relação ao equilíbrio que a natureza gera quando há presença constante e forte de áreas verdes, por exemplo. A capital paraibana possui $47,11 \mathrm{~m}^{2}$ de áreas verdes por habitante, segundo o Ministério do Meio Ambiente (2012), quase o triplo da média ideal recomendada pela Organização das Nações Unidas (ONU), que é de $15 \mathrm{~m}^{2}$. Além disso, a cidade possui o Jardim Botânico de João Pessoa (Figura 5), um dos maiores em extensão dentro de perímetro urbano no Brasil. 


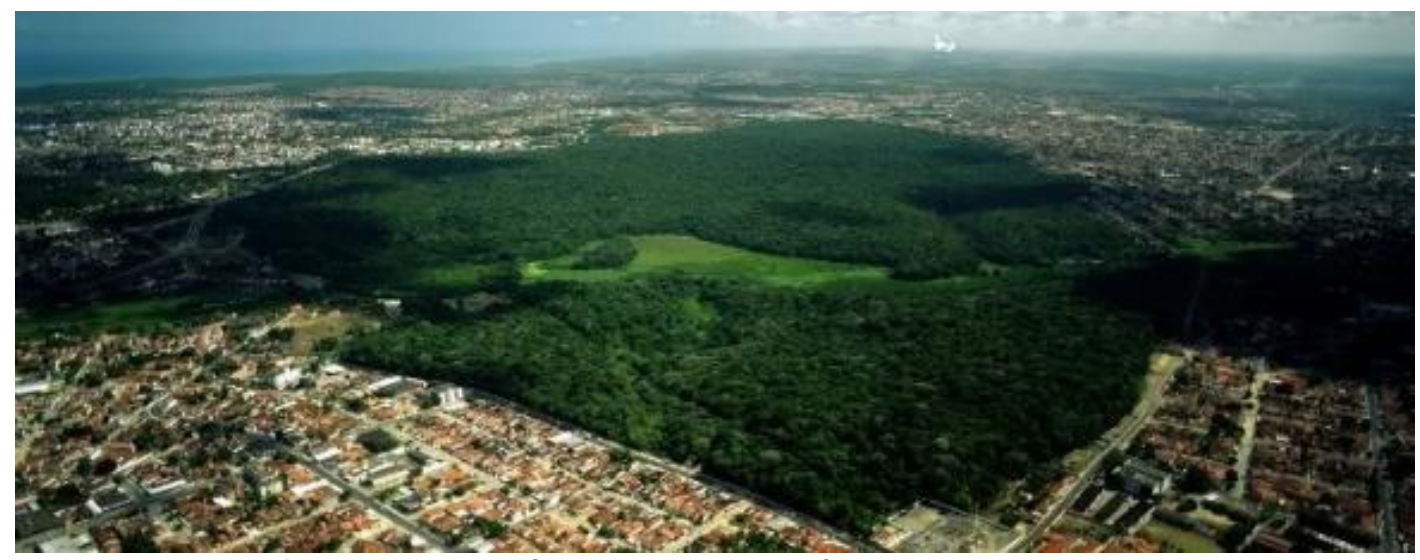

Figura 5: Vista aérea do Jardim Botânico de João Pessoa.

Figure 5: Aerial view of the Botanical Garden of João Pessoa.

Fonte: Dirceu Tortorello (2007).

Source: Dirceu Tortorello (2007).

Tal fato pode contribuir na percepção dos turistas acerca da temperatura adequada (ECO11), que foi a variável que obteve a maior média, já que as áreas verdes podem equilibrar a temperatura de uma localidade, caracterizando a adequação das sensações térmicas, proporcionar boa apresentação da qualidade do ar e água e, também, favorecer a percepção dos aspectos que beneficiam a geração da qualidade de vida para quem reside e visita o destino.

Nucci (2008) ratifica essa avaliação dos turistas de João Pessoa afirmando que as áreas verdes estabilizam de forma significativa as superfícies por meio da fixação do solo com a ação das raízes das plantas, além disso, criam obstáculos contra o vento; protegem a qualidade da água; filtram o ar; diminuem a poeira em suspensão; equilibram os índices de umidade no ar; reduzem o barulho; servem de abrigo para a fauna; e contribuem para a organização e composição de espaços no desenvolvimento das atividades humanas. Fores que caracterizam de forma positiva a alta qualidade ambiental.

Em contrapartida, os turistas percebem que, apesar dessas condições positivas apresentadas naturalmente neste local, os moradores poderiam ter um comportamento ambiental mais adequado. A média da variável ECO12, que fala deste comportamento que parte dos moradores, é de 3,91, que está abaixo da média geral desta dimensão e da média da ECO13, que fala da qualidade de vida. Ou seja, ainda que a cidade favoreça os aspectos que geram boa qualidade de vida aos moradores, na percepção dos entrevistados, estes possuem um comportamento abaixo do adequado de preservação, que siga a contribuição natural dos aspectos ambientais da cidade, significando uma perspectiva relativamente razoável nesta análise. Hall (2001) chama a atenção em relação ao comportamento ambiental da comunidade local afirmando que a "atitude dos residentes" (p. 229) devem ir em sentido às práticas de conservação, isto é, devem se tornar objetivo gerencial da comunidade. No mesmo sentido, Mattos (2005) ratifica que a qualidade ambiental, dependendo do aspecto analisado no momento, é reflexo das ações das pessoas que compõe aquele ambiente percebido. 
Já as variáveis que obtiveram as menores médias foram a ECO6 $(3,24)$, seguida das variáveis ECO2 $(3,72)$ e ECO8 $(3,83)$ :

-ECO6: O material informativo sobre a preservação ambiental em João Pessoa está facilmente disponível.

-ECO2: As lixeiras de coleta seletiva estão em locais adequados e de fácil acesso.

-ECO8: A coleta de lixo funciona de forma adequada mantendo as ruas sempre limpas.

As três variáveis estão relacionadas às ações que devem partir de órgãos governamentais (de ordem estadual e/ou municipal) para impedir a proliferação da poluição e promover a conscientização e sensibilização da conservação ambiental por parte dos moradores da cidade, como também, dos turistas que a visita. Por tanto, os turistas da pesquisa percebem que há pouco material informativo sobre essas questões, aspecto que Hall (2001) considera de muita importância não só em termos de educação ambiental, mas também na divulgação do turismo.

Além disso, as lixeiras, conforme opinião dos entrevistados, poderiam estar mais bem localizadas ou ter acesso mais fácil, e que a coleta desse lixo poderia funcionar de forma mais adequada, apesar das tentativas por partes dos órgãos competentes, como se observa na Figura 6, pois atende de forma regular à demanda dos turistas. Boersema (2009) afirma que isto pode acarretar uma impressão de repulsa podendo ocasionar numa publicidade negativa através da divulgação boca a boca após a visitação.

Nesse caso, Hall (2001) afirma: "uma comunidade mais sustentável está em harmonia com os sistemas naturais ao reduzir e transformar o lixo com propósitos benéficos e não prejudiciais" (p. 276), na tentativa de chamar a atenção para a importância da coleta do lixo e sua reutilização de forma sustentável.

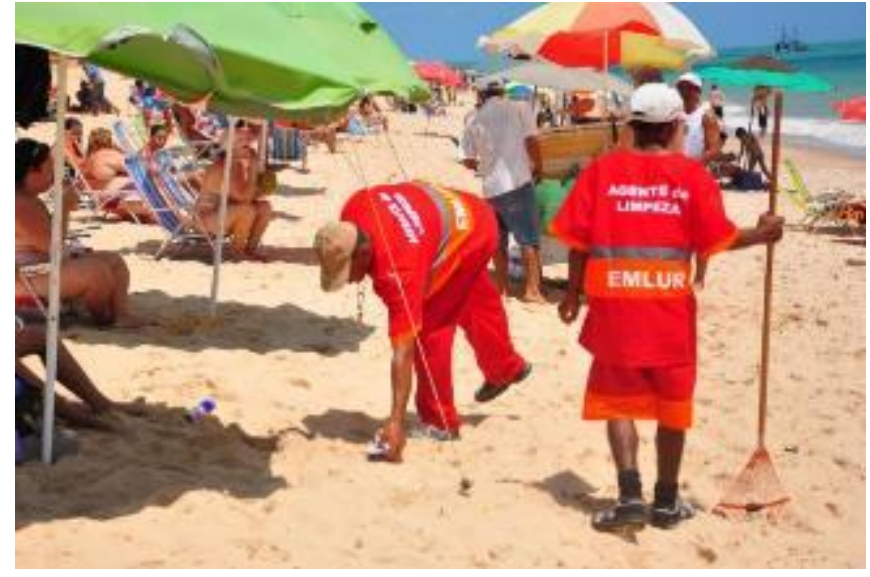

Figura 6 - Coleta de lixo na praia de Tambaú.

Figure 6 - Garbage collection at Tambaú beach.

Fonte: SEMAN (2016).

Source: SEMAN (2016). 
Um fato importante que deve ser destacado é que, apesar da maioria dos entrevistados estivessem visitando a cidade pela primeira vez (56\%), a percepção da qualidade ambiental não se diferenciou consideravelmente daqueles turistas que já haviam visitado anteriormente em outra ocasião (44\%), já que estes, por já terem visitado o destino, poderiam ter uma visão mais criteriosa por conhecerem os atrativos naturais de João Pessoa. Para exemplificar, tem-se a variável que obteve a maior média geral (ECO11, com $4,48)$, no caso dos turistas que estavam visitando pela primeira vez a média foi de 4,68 e no caso dos outros turistas que já haviam visitado a média dessa variável foi de 4,48. Isto demonstra que, apesar de uma possível percepção mais crítica da localidade, por parte dos turistas que retornaram ao destino, as médias se equiparam, e isso se repete em todas as outras variáveis, inclusive com diferença bem menores do que $0,20 \%$. O que se entende sobre isso é que a percepção da qualidade ambiental, tanto por turistas reincidentes quanto pelos turistas que estavam visitando pela primeira, não se difere tanto possivelmente devido à qualidade ambiental elevada que é apresentada na cidade em questão, através dos atrativos visitados.

Sobre as outras análises quantitativas, percebe-se, na tabela 1, que todas as variáveis da dimensão Ecotangibilidade apresentam assimetria negativa (ou à esquerda). Isto é, há uma curva de frequência unimodal que apresenta, a partir do seu ponto mais alto, uma "cauda" mais longa para esquerda, na prática isto quer dizer que, no caso dessa pesquisa, o valor da média é menor que a da mediana que é menor que a moda.

Em relação à curtose, as variáveis ECO2, ECO6, ECO8 e ECO12 apresentam curvas leptocúrticas, ou seja, isto quer dizer que a distribuição apresenta uma curva de frequência mais fechada (mais aguda em sua parte superior). Já as outras variáveis restantes, que é a maioria (9 de 13), apresentam curvas platicúrticas, quando apresenta uma medida de curtose menor que a da distribuição normal. Observa-se que, pelos valores obtidos de assimetria e curtose, todas as variáveis podem ser consideradas como tendo distribuição normal.

Já realizando-se a análise fatorial exploratória com as variáveis da dimensão Ecotangibilidade, verificou-se a composição de três subdimensões, que conforme a análise das variáveis e suas características, pôde-se defini-las como: a) sub-dimensão Ambiental, b) sub-dimensão Infraestrutura e c) sub-dimensão Visual.

Ressalta-se que a variável ECO6, que diz respeito à disponibilidade de material informativo sobre a preservação ambiental em João Pessoa, teve que ser excluída desta análise devido à apresentação de valores aproximados, quase iguais, das cargas fatoriais em duas das três subdimensões compostas (b e c). Quer dizer, para poder formular as subdimensões de forma criteriosa, a variável ECO6 teve que ser excluído pois, devido à média obtida, tanto na sub-divisão b quanto na $c$, a variável poderia se encaixar em ambas, então, para evitar conflito de formulação, preferiu-se excluir. 
Após essas explicações, apresenta-se a análise fatorial de cada subdimensão formulada de acordo com as cargas fatoriais:

A tabela 2, a seguir, retrata o agrupamento das variáveis ECO7, EC09, ECO1O, ECO11 e ECO13 na sub-dimensão ambiental, que referenciam assuntos diretamente ligados ao meio ambiente, como pode ser observado nos itens descritos - por isso a determinação do nome "ambiental" para nomeá-la.

Tabela 2: Análise Fatorial da Sub-Dimensão Ambiental da Ecotangibilidade.

Table 2: Factorial Analysis of Ecotangibility Environmental Sub-Dimension.

\begin{tabular}{c|l|c}
\hline Item & \multicolumn{1}{c}{ Variáveis } & \begin{tabular}{c}
\multicolumn{1}{c}{ Carga } \\
Fatorial
\end{tabular} \\
\hline ECO7 & As praias de João Pessoa estavam sempre limpas. & 0,714 \\
\hline ECO9 & João Pessoa apresenta boa qualidade do ar. & 0,849 \\
\hline ECO10 & João Pessoa apresenta boa qualidade da água. & 0,835 \\
\hline ECO11 & A temperatura de João Pessoa é adequada. & 0,761 \\
\hline ECO13 & $\begin{array}{l}\text { A cidade de João Pessoa tem aspectos que geram boa } \\
\text { qualidade de vida para os moradores. }\end{array}$ & 0,759 \\
\hline
\end{tabular}

KMO (Kaiser-Meyer-Olkin): 0,836

Bartlett's Test of Sphericity: 759,914 Sig:0,000

Variância: $61,640 \%$

Alfa de Cronbach: 0,840

Eigenvalue: 3,082

Fonte: Resultado da pesquisa (2014).

Source: Search results (2014).

A Tabela 3, em seguida, foi definida com o agrupamento das variáveis ECO3, ECO4, ECO8 e ECO12 na sub-dimensão infraestrutura, de acordo com os assuntos diretamente ligados à estrutura pela qual os turistas fazem percepção e, também, como o comportamento dos moradores refletem conforme essa estrutura. Tal fato pode ser reparado nos itens descritos.

Tabela 3; Análise Fatorial da Sub-Dimensão Infraestrutura da Ecotangibilidade.

Table 3; Factorial Analysis of the Sub-Dimension Ecotangibility Infrastructure.

\begin{tabular}{c|l|c}
\hline Item & \multicolumn{1}{c}{ Variáveis } & $\begin{array}{c}\text { Carga } \\
\text { Fatorial }\end{array}$ \\
\hline ECO3 & $\begin{array}{l}\text { Os aspectos arquitetônicos da infraestrutura de João Pessoa, } \\
\text { acesso, sinalização, estacionamento, etc. estão integrados à } \\
\text { paisagem local. }\end{array}$ & 0,814 \\
\hline ECO4 & $\begin{array}{l}\text { A infraestrutura dos atrativos turísticos de João Pessoa é } \\
\text { adequada ao meio ambiente. }\end{array}$ & 0,808 \\
\hline ECO8 & $\begin{array}{l}\text { A coleta de lixo funciona de forma adequada mantendo as ruas } \\
\text { sempre limpas. }\end{array}$ & 0,731 \\
\hline ECO12 & Os moradores de João Pessoa têm comportamento ambiental. & 0,751 \\
\hline
\end{tabular}

KMO (Kaiser-Meyer-Olkin): 0,749

Bartlett's Test of Sphericity: 432,831 Sig:0,000

Variância: $60,338 \%$

Alfa de Cronbach: 0,777

Eigenvalue: 2,414

Fonte: Resultado da pesquisa (2014).

Source: Search results (2014). 
E na Tabela 4, a seguir, observa-se o agrupamento das variáveis ECO1, ECO2 e ECO5 em uma subdimensão. Tais variáveis correspondem às características visuais da cidade de João Pessoa percebidas pelos turistas, como está bem explicado na descrição dos itens dessa subdimensão, justificando tal agrupamento conforme análise fatorial.

Tabela 4: Análise Fatorial da Sub-Dimensão Visual da Ecotangibilidade.

Table 4: Factorial Analysis of the Ecotangibility Visual Sub-Dimension.

\begin{tabular}{c|l|c}
\hline Item & \multicolumn{1}{|c}{ Variáveis } & $\begin{array}{c}\text { Carga } \\
\text { Fatorial }\end{array}$ \\
\hline ECO1 & $\begin{array}{l}\text { No geral, o aspecto visual de João Pessoa está em bom estado } \\
\text { de conservação. }\end{array}$ & 0,799 \\
\hline ECO2 & $\begin{array}{l}\text { As lixeiras de coleta seletivas estão em locais adequados e de } \\
\text { fácil acesso. }\end{array}$ & 0,819 \\
\hline ECO5 & $\begin{array}{l}\text { A preservação do meio ambiente de João Pessoa está em bom } \\
\text { estado. }\end{array}$ & 0,801 \\
\hline
\end{tabular}

KMO (Kaiser-Meyer-Olkin): 0,684

Bartlett's Test of Sphericity: 241,469 Sig:0,000

Variância: $65,021 \%$

Alfa de Cronbach: 0,729

Eigenvalue: 1,951

Fonte: Resultado da pesquisa (2014).

Source: Search results (2014).

Referindo-se aos valores obtidos no KMO das três sub-dimensões, tem-se: a) Sub-dimensão Ambiental 0,836, b) Sub-dimensão Infraestrutura 0,749 e c) Sub-dimensão Visual 0,684. Constata-se que todas têm posição positiva da adequação da amostra determinada para o estudo. Sendo que pontuam de forma diferente: a) mertorius, b) midding e c) medíocre. Ressalta-se que a medida de adequação da amostra KMO pode ser classificada conforme os valores apresentados, sendo apropriados para realização de análise fatorial. Segundo Malhotra (2006), a classificação dos valores é: 0,9 ou mais significa marvelous $4,0,8$ ou mais significa mertorious, 0,7 ou mais midding, 0,6 ou mais significa medíocre, 0,5 ou mais significa miserable e abaixo de 0,5 significa inaceptable. Ou seja, de acordo como o que foi achado nessa pesquisa, há uma hierarquia da adequação dentro da dimensão Ecotangibilidade no que concernem os aspectos ambientais, da infraestrutura e visuais, nessa ordem de apresentação.

As três sub-dimensões lograram significância de 0,000 no teste de esfericidade de Bartlett o que favorece a correlação entre as variáveis desta dimensão. O coeficiente Alfa de Cronbach, das três sub-dimensões, apresentam alta confiabilidade interna em seus itens, apontando alta consistência das questões propostas no questionário para caracterizar a sub-dimensão, já que este coeficiente teve, respectivamente: a) 0,840, b) 0,777 e c) 0,729 . Ou seja, a análise fatorial empregada neste item aponta para alta consistência nos constructos elaborados, confirmando a hierarquização entre as sub-dimensões criadas. 


\section{Considerações finais}

A presente pesquisa, para efeitos de conclusão, objetivou a análise da percepção da qualidade ambiental no destino turístico João Pessoa (PB), através do olhar do turista que a visitou, utilizando as variáveis da dimensão Ecotangibilidade de Kahn (2003). Tais variáveis têm o intuito de entender como os serviços turísticos, suas instalações, os serviços públicos voltados para o meio ambiente $e$ as características ambientais do local se apresentam aos turistas e se estes percebem essas dimensões de forma mais positiva ou menos positiva.

Num primeiro momento, de forma geral, conclui-se que os turistas entrevistados na pesquisa concordam parcialmente ou plenamente que as características ambientais, relacionadas ao turismo, estão de acordo com o que foi apresentado. Isto é, os turistas entendem que João Pessoa possui qualidade ambiental satisfatória, principalmente quando se fala em questões como temperatura, qualidade do ar, qualidade da água e aspectos que geram qualidade de vida para os moradores do destino. Ressalta-se que até as variáveis que obtiveram as menores médias, estas médias não foram, de forma alguma, avaliadas como negativas. Por exemplo, a variável ECO6, que trata sobre a disponibilidade de informativos que falam de preservação ambiental no destino, obteve média de 3,24 numa escala entre 1 e 5, apontando, portanto, para uma avaliação de espectro positivo e acima de uma avaliação mediana. O que caracteriza uma percepção positiva de todos os aspectos avaliados em todas as dimensões.

Em se tratando da análise fatorial, pôde-se observar que foi possível subdividir as variáveis da dimensão Ecotangibilidade em três subdimensões: ambiental, infraestrutura e visual. Dentre essas três, a ambiental obteve melhor avaliação, indicando que as características naturais do destino se sobrepõem às características modificadas ou de responsabilidade das pessoas/governo do destino. Com esse resultado, entende-se que a sociedade como um todo (moradores, empresas privadas e poder público) precisa prestar mais atenções aos detalhes ambientais da cidade, ou seja, criar mecanismos de gestão e planejamento que estejam à altura dos aspectos naturais e do meio ambiente que estão disponíveis para todos (comunidade local e turistas. Dessa forma, pode-se investir mais em conscientização dos usos naturais, preservação da natureza e evitar ou minimizar a degradação e poluição do destino como um todo.

Por fim, a pesquisa mostra-se importante para apontar que o destino turístico João Pessoa, apesar da análise positiva dos aspectos voltados para a qualidade ambiental, necessita de avaliação e manutenção constante da prática turística. A fim de manter-se como destino turístico de vocação natural e que, por fim, tal avaliação pelos turistas continue de forma positiva. 


\section{Notas:}

${ }^{1}$ Ferramenta de referência rápida que define os principais termos usados nas áreas de meio ambiente, estatísticas, indicadores de desenvolvimento sustentável e de contabilidade ambiental e econômica integrada.

${ }^{2}$ Agência da União Europeia que tem a tarefa de fornecer informações sobre o ambiente. É uma fonte de informação importante para aqueles que estão envolvidos no desenvolvimento e avaliação de políticas ambientais, e também o público em geral.

3 Ecoturistas são os adeptos do ecoturismo. Ecoturismo de acordo com The EcoturismSociety é defnida como "viagem responsavel a áreas naturais que conserva o meio ambiente, sustenta o bem-estar das populações locais, e envolve interpretação e educação (TIES, 2015). Para maior aprofundamento no tema acesse: https://www.ecotourism.org/what-is-ecotourism.

${ }^{4}$ Salienta-se que a tradução não foi feita temendo a não fidelidade ao real sentido com a qual os termos em questão foram utilizados pelos autores.

\section{Referências}

ANJOS, F. A.; ANJOS, S. J. G.; RADOS, G. J. V. Planejamento e gestão sustentável do turismo: contexto social, métodos e enfoques. In: PHILIPPI JR., A.; RUSCHMANN, D. V. D. M. Gestão ambiental e sustentabilidade no turismo. Barueri, SP: Manole, 2010.

ARAÚJO, C.M. Ética e Qualidade no Turismo do Brasil. São Paulo: Atlas, 2003.

BASSANI, M. A. Fatores psicológicos da percepção da qualidade ambiental. In: MAIA, N. B.; MARTOS, H. L.; BARELLA, W. (Orgs.). Indicadores Ambientais: conceitos e aplicações. São Paulo: EDUC, 2001.

BENI, M. C. Análise Estrutural do Turismo. 7ed. São Paulo: Editora SENAC, 2002.

BITAR, O. Y. Meio ambiente \& geografia. São Paulo: SENAC, 2004.

BOERSEMA, J. J. Environmental sciences, sustainability and quality. In: BOERSEMA, J. J.; REIJNDERS, L. Principles of Environmental Sciences. Amsterdam: Springer, 2009.

BORELLI, E. Urbanização e qualidade ambiental: o processo de produção do espaço da Costa Brasileira. Revista Internacional Interdisciplinar Interthesis, v. 4, n. 1, p. 1-27, 2007.

BRASIL. País está mais consciente. Ministério do Meio Ambiente. Disponível em http://www.mma.gov.br/informma/item/8588-pa\%C3\%ADsest\%C3\%A1-mais-consciente. Acesso em: 05/02/2018.

CORRAR, L. J.; PAULO, E.; DIAS FILHO, J. M. (Coord.). Análise multivariada: para os cursos de Administração, Ciências Contábeis e Economia. São Paulo: Atlas, 2012.

CRONIN, J.; TAYLOR, S. Measuring service quality: A reexamination and extension. Journal of Marketing, v. 56, n. 3, p. 55-68, 1992. 
DEBEUS, G.; CRISPIM, M. C. O turismo nas piscinas naturais de Picãozinho, João Pessoa-PB - Percepções, conflitos e alternativas. REA Revista de estudos ambientais, v. 10, n 1, p. 21-32, 2008.

FERNANDES, R. S.; SOUZA, V. J.; PELISSARI, V. B; FERNANDES, S. T. Uso da percepção ambiental como instrumento de gestão em aplicações ligadas às áreas educacional, social e ambiental. 2009. Disponível em: http://www.redeceas.usp.br/noticias/Percepcao Ambietal.pdf. Acessado em: 02 fev. 2018.

FULGÊNCIO, P. C. Glossário vade mecum. Rio de Janeiro: Mauad, 2007. p. 678 p.

GOMES, M. A. S.; SOARES, B. R. Reflexões sobre qualidade ambiental urbana. Estudos Geográficos, v. 2, n. 2, p. 21-30, 2004.

HALL, C. M. Planejamento turístico: políticas, processos e relacionamentos. São Paulo: Contexto, 2001.

JOHNSON, D. L.; AMBROSE, S. H.; BASSET, T. J.; BOWEN, M. L.; CRUMMEY, D. E.; ISSACSON, J. S.; JOHNSON, D. N.; LAMB, P.; SAUL, M.; WINTER-NELSON, A. E. Meanings of Environmental Terms. Journal of Environmental Quality. v. 26, n. 3, p. 581-589, 1997.

GIL, A. C. Métodos e técnicas de pesquisa social. São Paulo: Atlas, 1999.

KHAN, M . ECOSERV: Ecotourist's quality expectations. Annals of Tourism Resarch, v. 30, n. 1, p. 109-124, 2003.

MALHOTRA, N. Pesquisa de Marketing: Uma orientação aplicada. Tradução Laura Bocco. 4. Ed. Porto Alegre: Bookman, 2006.

MARÔCO, J. Análise de Equações Estruturais. Fundamentos teóricos, software e Aplicações. PSE Produtos e Serviços Estatísticos Ltda, 2010.

MATTOS, S. H. V. L. Avaliação da qualidade ambiental da bacia hidrográfica do córrego do Piçarrão (Campinas-SP). 96f. Dissertação (Mestrado). Universidade Estadual de Campinas, Instituto de Geociências. 2005.

MOTA, S. Urbanização e meio ambiente. Rio de Janeiro: ABES, 1999.

NUCCI, J. C. Qualidade ambiental e adensamento urbano: um estudo de ecologia e planejamento da paisagem aplicado ao distrito de Santa Cecília (MSP). 2 ${ }^{a}$ ed. Curitiba: O Autor, 2008.

PACHECO, É.; SILVA, H. P. Compromisso Epistemológico do Conceito de Percepção Ambiental. Rio de Janeiro: Departamento de Antropologia, Museu Nacional e Programa EICOS/UFRJ, 2007. Disponível em: http://www. ivtri.net/sapis/2006/pdf/EserPacheco.pdf. Acessado em: 04/02/2018.

PARASURAMAN, A. L.; BERRY, L.; ZEITHALML, V. A conceptual model of service quality and its implications for future research. Journal of Marketing, v. 49 , n. 4 , p. $41-50,1985$.

PIRES, P. S. Turismo e meio ambiente: relação de interdependência. IN: PHILLIPI JR., A.; RUSCHMANN, D. V. M. Gestão ambiental e sustentabilidade no turismo (Coleção Ambiental, v.9). Barueri, SP: Manole, 2010. 
REIS, I. C. S. A escala SERVQUAL modificada: avaliação da qualidade percebida do serviço de lazer oferecido por um complexo poliesportivo num parque florestal. Dissertação de Mestrado. UFSC. Florianópolis / SC. 2001.

SACHS, I. Caminho para o desenvolvimento sustentável. Rio de Janeiro: Garamond, 2000.

Bruno Lima Machado: Universidade Federal de Minas Gerais, Belo Horizonte, MG, Brasil.

E-mail: brunolmachado@gmail.com

Link para o currículo Lattes: http://lattes.cnpq.br/0743392312262152

Data de submissão: 29 de novembro de 2018

Data de recebimento de correções: 13 de abril de 2019

Data do aceite: 13 de abril de 2019

Avaliado anonimamente 